\title{
ENVIRONMENTAL MANAGEMENT AND RECREATIONAL FACILITIES USAGE: A STUDY OF KAINJI LAKE NATIONAL PARK
}

\author{
Kolawole G.T. Omotayo O.L., Adedeji E.O., Chikezie J., Attahiru H. \\ Federal College of Wildlife Management, \\ New Bussa, Niger State, Elizabeth Abidemi Akintade \\ Federal University of Technology, Akure
}

\begin{abstract}
Assessment of Environmental and Recreation Facility Maintenance was carried out in Kainji Lake National Park. Questionnaire method of data collection was employed to collect the data needed. Purposive and simple random techniques were adopted to sample respondents in the study area. One hundred questionnaires were designed and administered. The data collected were analyzed through simple percentage and presented in table and charts. However, the results showed that recreation facilities are $99 \%$ present, while swimming pool is $65 \%$ functional. The study showed that visitors came there three times in a week indicating $44 \%$ of the respondents while on maintenance of the park environment and the facilities indicated $94 \%$ and $88 \%$ of the respondents respectively. The study further recommended the followings facilities basketball pitch. Hockey game, volley ball and well-constructed swimming pool.
\end{abstract}

KEYWORDS: environment, maintenance, recreation, facilities, usage, park

\section{INTRODUCTION}

While there may be a temptation to think of recreation as trivial, even frivolous, most of us know better. As paradoxical as it might seem, recreation is a serious matter. The importance of recreation manifests itself in a number of ways. Perhaps the most obvious to readers of the George Wright forum is the philosophical and legal foundation of U.S National Park as laid down in the National Park Service of Organic Act Of 1916. While national parks are clearly to be conserved, they are also to "provide for the enjoyment of the people. This two - fold mission is at the heart of most public parks and related areas. Thus, recreation, in a variety of forms is vital even integral top parks.

The etymology of the word "recreation" is also suggestive of the importance of its role in society rooted in the Latin "recreation" and "recreare" "recreation" means respectively "to refresh" and "to restore" (Edginton, eta al., 2002). Given the increasing Dace and stress of contemporary society, it seems likely that recreation will continue to grow in importance, and that parks will likewise escalate in importance for their role in providing public recreation. The social importance of recreation is further reflected in the professional activity and literature that has grown up around it. There is a received history of the "recreation movement" in the US, a social movement designed to provide the benefits of recreation to all Americans. Students can now earn degree in recreation, parks and a related field at over 50 colleges requires information on values of recreation. Whether for damage assessment or Government Performance and Results Act (GPRA) of 1993 these requirement feeds directly into a need for credible measures of benefits. Tourism and protected areas have been intimately related for centuries with notable implications. Since, or perhaps even before, the establishment of yellow 
stone in 1872. Tourism has been much depending on the outstanding natural lands Cape in protected areas for its survival and to operate. In 2004, the segment of tourism in natural areas grew three times faster than the entire tourism industry as a whole. This growth is believed to be also result from the increase in the number of protected area worldwide. According to IUCN and WCMC (2003), the number of protected areas worldwide had grown 1, 000 in 1960s to over 100, 000 in 2002. A protected area is defined as areas of land and or sea especially dedicated of natural and associated cultural resources and managed through legal or other effective means. Based on the principles of sustainable tourism, tourism is able to support these roles of parks (Driver, 1990; Driver 1996; Stein and Lee 1995; Allen 1996). Recreation activities are basic tools for people's empowerment there are several benefits derivable from recreation if properly harnessed and the environment are properly maintained. However the environmental maintenance and recreational facilities of some parks are under maintained because of some reasons peculiar to them. This will however make this work to focus on Kainji Lake National Park.

The aims of this research work are to: access on the recreational facilities available at Kainji Lake National Park,to examine the level of maintenance of the recreational facilities at Kainji Lake National Park, to access the maintenance of the park environment for visitors delight

\section{METHODOLOGY}

This study made use of quantitative method (the use of questionnaire to collect data from respondents. A total of 100 respondents were drawn through simple random and systematic sampling in the park.Questionnaire as the major instrument designed for data collection. The questionnaire was designed to contain questions that were related to the topic of the research.The target populations for this study were staff of the park and also tourists of both sexes (male and female).Purposive and simple random techniques were employed to sample respondents for this study, thus, 100 questionnaires were design and administered to the staff of the park.

\section{PRESENTATION OF DATA/RESULTS}

Descriptive statistics were employed for the data analysis where result were shown in table, charts etc. 
Table 1: Availability of recreational facilities

\begin{tabular}{lcc} 
Options & Frequency & Percentage \\
Yes & 99 & 99 \\
No & 1 & 1 \\
\hline Total & $\mathbf{1 0 0}$ & $\mathbf{1 0 0 \%}$ \\
\hline
\end{tabular}

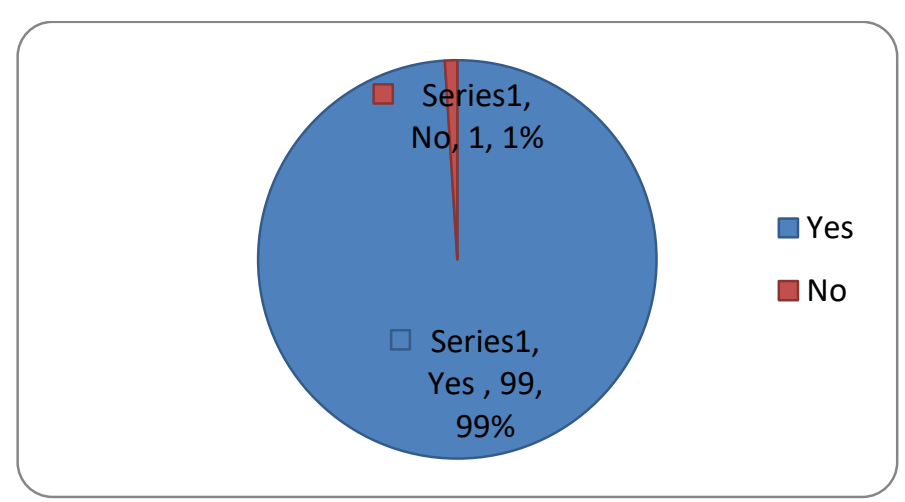

Figure 1

According to the above on the whether recreational facilities are available in the park $99 \%$ of the respondents in the study area claimed that recreational facilities are available while $1 \%$ of the respondents said no.

Table 2: Identified recreational facilities

\section{Options}

Swimming pool

Table tennis

Football pitch

Basketball court
Frequency

65

14

11
Percentage \%

65

14

11

$\begin{array}{lll}\text { Total } & 100 & 100 \%\end{array}$

Figure 2:

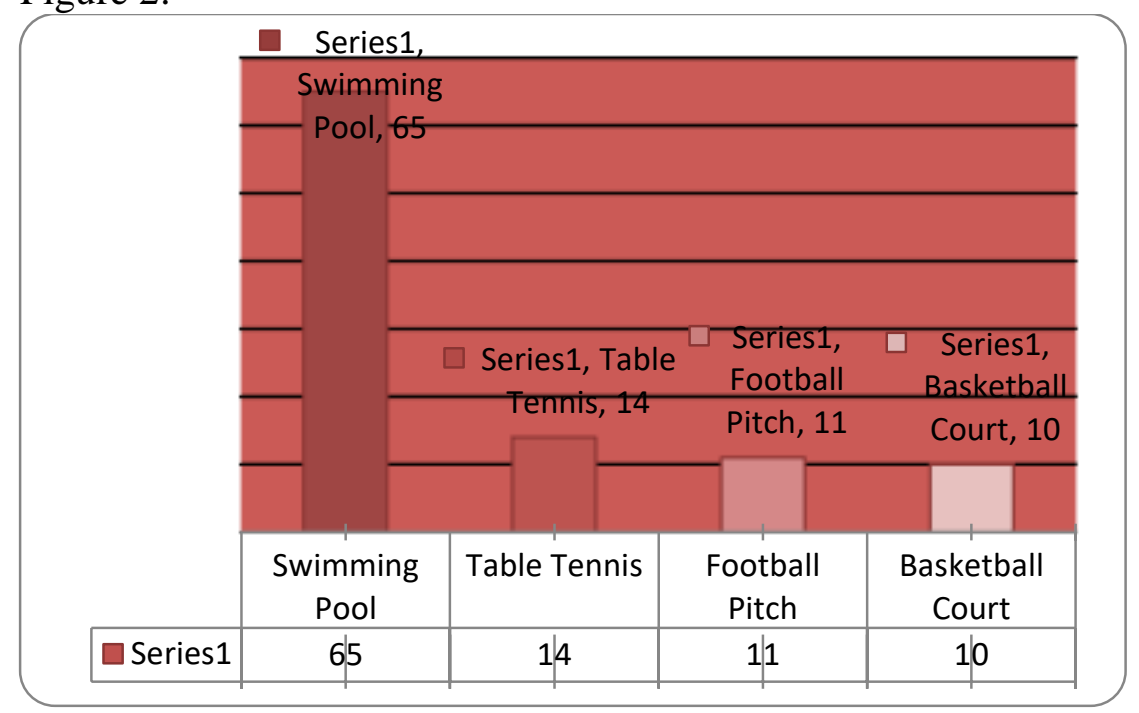


The above on the identified recreational facilities $65 \%$ of the respondents claimed that swimming pool is available and much more functional than other facilities while followed by table tennis which stands at $14 \%$. The reason for the low responses is attached with the improvement that the facilities needed.

However, the facilities recommended for recreation purposes are listed below;

i. $\quad$ New basketball field

ii. Hockey pitch

iii. Lawn tennis court

iv. Well-equipped museum

v. Bat mitting

vi. Volley ball pitch.

Table 3: Tourist patronage

\section{Options}

Weekly

Once a year

Frequency Percentage \%

3 times a week

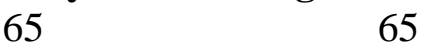

$14 \quad 14$

$11 \quad 11$

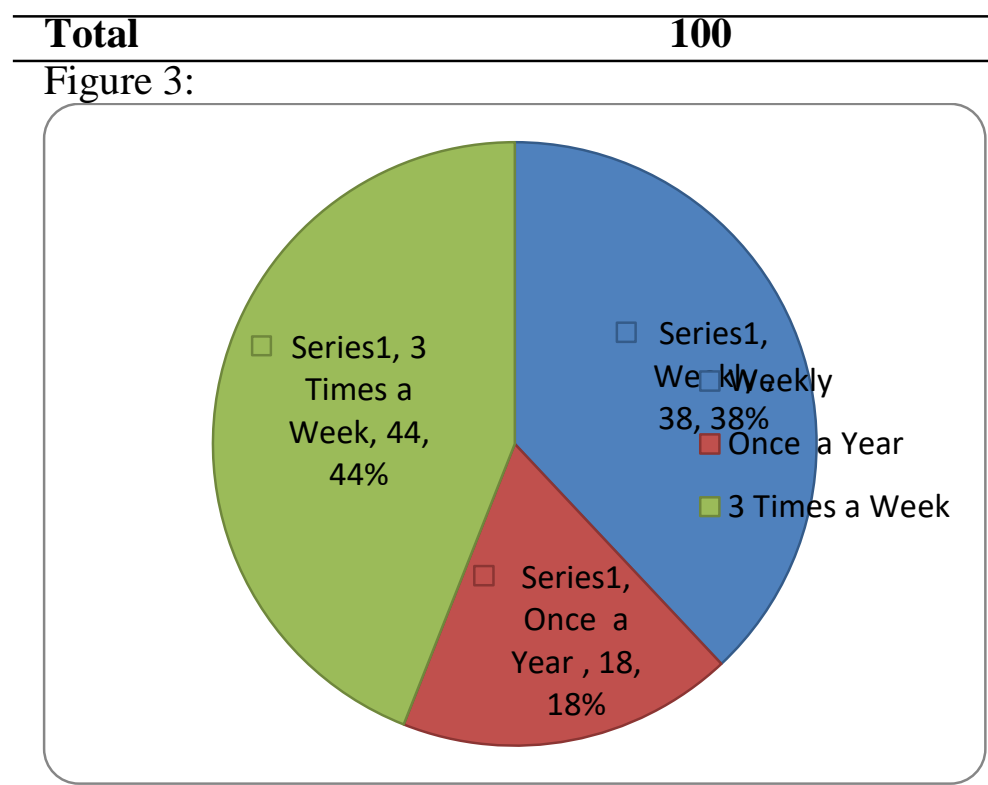

The chart above shows that tourists come to the park three times in a week have $44 \%$ of the total respondents, while those that come there weekly $38 \%$ of the respondents followed by those that come their once in a year which have $18 \%$ of the respondents.

Table 4: Level of maintenance of recreational facilities

\begin{tabular}{lcc} 
Options & Frequency & Percentage \% \\
Yes & 88 & 88 \\
No & 12 & 12 \\
\hline Total & $\mathbf{1 0 0}$ & $\mathbf{1 0 0 \%}$ \\
\hline
\end{tabular}


Figure 4:

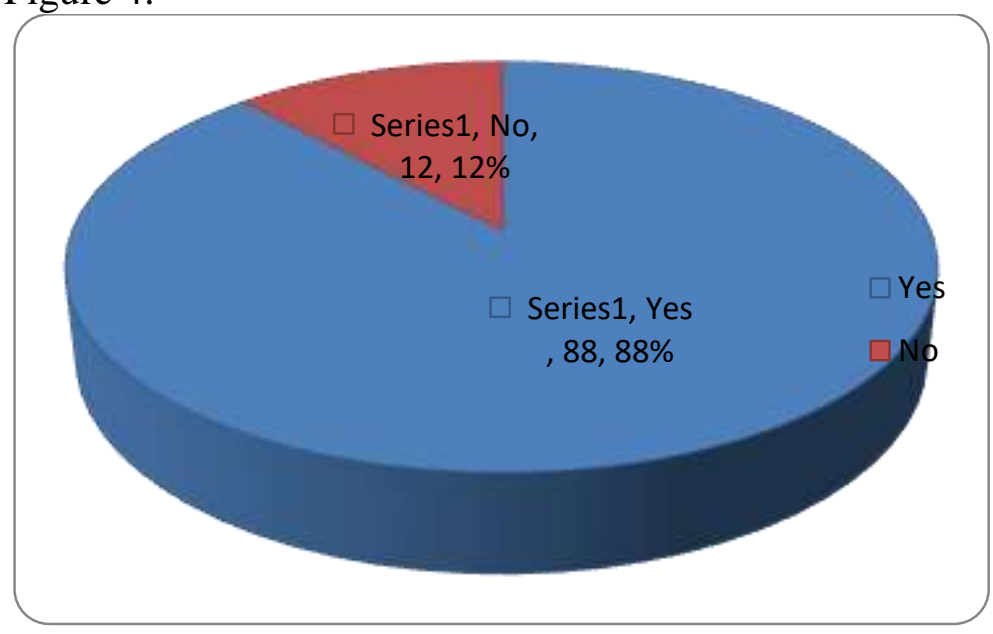

The above chart indicated the level of maintenance of recreational facilities available in the park. $88 \%$ of the respondents claimed that they are well maintained and the rate at which the facilities are maintained is high when $12 \%$ of the respondents claimed that the maintenance is low. However, on whether the maintenance is high or not the same percentage of 88 claimed it is high.

Table 4: Environmental maintenance of the park

\begin{tabular}{lcc} 
Options & Frequency & Percentage \% \\
Yes & 94 & 94 \\
No & 6 & 6 \\
\hline Total & $\mathbf{1 0 0}$ & $\mathbf{1 0 0 \%}$ \\
\hline
\end{tabular}

Figure 5:

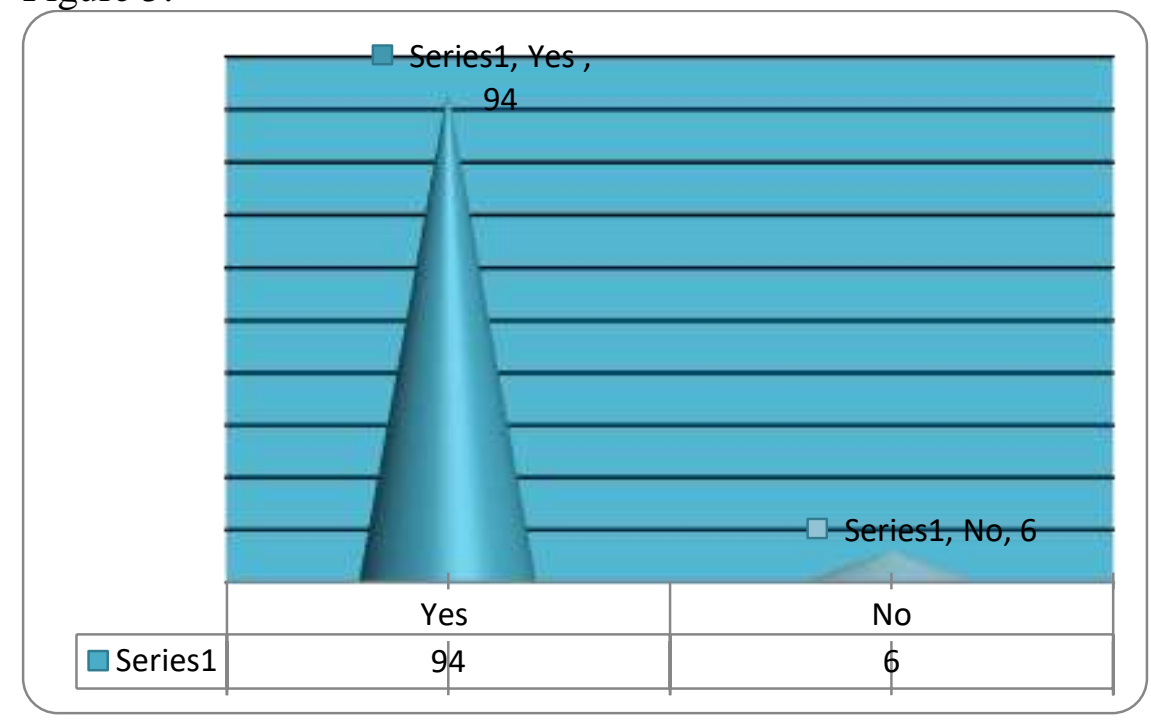

The chart above shows that the park environment is well maintained this is because $94 \%$ of the total respondents claimed that the environment is well maintained, while $6 \%$ claimed no. 


\section{CONCLUSION AND RECOMMENDATION}

Based on the result gathered on the study as the park environment is well maintained and cared for and more so as the facilities are available but of old, it is now concluded that the rate at which the tourists supposed to be flowing to the park is limited because of that shortcoming. Therefore, for the park to experience more influx weekly, monthly and yearly the facilities must be changed to modern day recreation facilities to encourage the users. Also enough funds must be given to the park for adequate management. As the result of the study has shown that tourists use to come to the park weekly, monthly, and yearly, as a result of proper maintenance of the environment and adequate supply of modern day facilities. It is also recommended that other recreational facilities like; basketball, hockey game, volleyball, indoor games should be out in place for the use of the tourists. On the part of the government enough found should be appropriated to the park, while enough staff should be employ for proper surveillance of the park and enough education should be given to the public to sustain the park

\section{REFERENCES}

Bruce (1995). Tourism has recognized that many visitors are specifically attracted recreational offerings. Pp. 51 - 53

Christine (2006). Indulge in things you love and see the world through a new perspective. P. 30

Cranz, (1982).The recognized that public action was required to achieve these goals in Taylor (1999).Pp 34 - 35

Danny (2006).Encouragement of people to take recreational activities from time to time.pp $16-19$.

Dewey (1954). Many private acts are socially; their consequences contribute to the welfare of the community or affect its status and prospects. P 21

Eastleigh (2007). In the economic aspect, promoting physical activities for employees makes good business sense. Pp $4-6$.

Immanuel (1982). Participation in recreation activities had no significant positive relation to life satisfaction in retirement. Pp 22 - 25

Jacques (2000).Research show that recreational activities contribute to the satisfaction of life, health and also improve the quality of the life. P. 51

Karen et al (2006). Skateboarding might be a fun away to spend time and enjoy the beauty of your lovely neighbourhood or even meet your friends around the corner. $\mathrm{Pp} 33$ 39

McLean (2005).Increased commercialization of recreational offerings.

Mireille (2001). Zoos also hire animal caretakers, guides maintenance workers, and public relation personnel. P 14

More (2002). In the past, public park and recreation have been cast in the same mold. Pp $11-15$

Okun (1975). Private markets are efficient, but they may not treat people equally. Pp. 71 74

O'Neil (1993). Recreation is undoubtedly the must widespread public value associated with park, as indicated by the state park survey. p. 3 
Steve (1993). Changing demographics and lifestyle also have an impact on employment in hospitality and recreation. Pp. $101-112$

Thomas (1970). Considered enjoyment, amusement or pleasure to be "fun"

Rysing (2003). Recreational potential of landscape is "degree of possibility to perform its recreational functions condition by its nature features as well as results of human activities". p 220. 